\title{
Método rápido de avaliação do esverdeamento em tubérculos de batata(1)
}

\author{
Sieglinde Brune(2) e Paulo Eduardo Melo(2)
}

\begin{abstract}
Resumo - Em batata, as sínteses de clorofila e glicoalcalóides são induzidas pela luz, conferindo, respectivamente, esverdeamento e sabor amargo aos tubérculos. O objetivo deste trabalho foi identificar um método rápido para avaliação da resistência ao esverdeamento dos tubérculos de batata. Tubérculos de clones-elite e das cultivares Achat (suscetível) e Bintje (resistente) foram lavados e avaliados visualmente quanto ao esverdeamento (escala de notas de cinco pontos) após 5, 10, 15 e 20 dias de exposição à luz (250 lux). Cinco dias de exposição à luz foram suficientes para separar as cultivares Bintje (nota 1,0) e Achat (nota 3,0) em classes distintas. Porém, foram necessários 20 dias de exposição à luz para identificar com precisão boas fontes de resistência. A análise das épocas de avaliação por meio de componentes principais não proporcionou uma clara separação dos genótipos em classes de resistência ao esverdeamento. Considerando cada leitura, foram selecionados, por seu valor per se e para uso em melhoramento, os clones CNPH-036 e CNPH-065 (resistentes ao esverdeamento) e CNPH-039 e CNPH-063 (de resistência moderada, mas consistente). Os clones CNPH-009 e CNPH-019 mostraram reação variável ao longo do tempo e, por isso, devem ser considerados apenas por seu valor per se.
\end{abstract}

Termos para indexação: Solanum tuberosum, resistência ao enverdeamento, métodos de melhoramento.

\section{A quick method to assess greening in potato tubers}

Abstract - In potato, both chlorophyll and glycoalkaloids syntheses are light induced, being responsible for the development of greening and a bitter taste in potato tubers, respectively. This work was carried out aiming at identifying a quick method to assess resistance to tuber greening in potato. Tubers of elite-clones, as well as of cultivars Achat (susceptible) and Bintje (resistant) were washed and visually assessed to greening (five-point scale) after 5, 10, 15, and 20 days of exposure to light (250 lux). A five-day exposure was enough to place cultivars Bintje (grade 1.0) and Achat (grade 3.0) in distinct classes. However, only after a 20-day exposure, an accurate identification of resistance sources was possible. Principal component analysis was used to group the evaluation dates. However, it did not provide a clear-cut separation of genotypes in classes of resistance to tuber greening. Taking into account the results obtained in each evaluation date, clones CNPH-036 and CNPH-065 (resistant to greening), and clones CNPH-039 and CNPH-063 (moderately, but consistently resistant) were selected. All four clones showed value per se and for breeding. Clones CNPH-009 and CNPH-019 had a variable reaction in time concerning greening and, although having value per se, are not recommended for breeding purposes.

Index terms: Solanum tuberosum, greening discoloration, breeding methods.

\section{Introdução}

Por ser grande a importância econômica de cultivares de batata com tubérculos resistentes ao esverdeamento, esta característica é alvo de preocu-

\footnotetext{
(1) Aceito para publicação em 9 de agosto de 2000 .

(2) Embrapa-Cento Nacional de Pesquisa de Hortaliças, Caixa Postal 218, CEP 70359-970 Brasília, DF.

E-mail: linde@cnph.embrapa.br,paulo@cnph.embrapa.br
}

pação dos melhoristas em muitos países (Guarda, 1986; Zan \& Baruzzini, 1991; Dale et al., 1994; Tan \& Haynes, 1996). No Brasil, o problema é agravado pela prática de comercializar tubérculos lavados, expostos a granel ou em sacos rendilhados. Os principais fatores responsáveis pelo esverdeamento dos tubérculos são a síntese e o acúmulo de clorofila (MurajaFras et al., 1994), decorrentes da exposição à luz e conseqüente transformação de amiloplastos em cloroplastos (Conover \& Pryke, 1987). A exposição 
dos tubérculos à luz induz também a síntese e acúmulo de glicoalcalóides nos tubérculos (Reeves, 1988), especialmente $\alpha$-solanina e $\alpha$-chaconina (Dao \& Friedman, 1994). Esses glicoalcalóides, quando em concentrações elevadas, conferem aos tubérculos um sabor amargo e picante, e podem causar intoxicação alimentar, quando ingeridos em grandes quantidades (Maine et al., 1988). Embora não tenham participação no esverdeamento dos tubérculos, o fato de a síntese desses alcalóides ser, como a da clorofila, induzida pela luz, leva os consumidores a associar o esverdeamento ao sabor amargo (Kaaber, 1993). A sensibilidade à luz, e, como resposta, a velocidade $\mathrm{e}$ a intensidade de esverdeamento, são muito dependentes da quantidade e intensidade de luz a que são expostos os tubérculos (Brown \& Riley, 1976). A intensidade de esverdeamento dos tubérculos de batata quando expostos à luz possui também um componente genético, que resulta em diferenças nas reações dos genótipos quando expostos às mesmas condições indutoras (Griffiths et al., 1994). A característica possui herança quantitativa, com dominância incompleta (Akeley et al., 1962). Porém, a herdabilidade é grande o suficiente para permitir ganhos de seleção consistentes (Parfitt \& Peloquin, 1981). Sendo assim, é possível selecionar clones em programas de melhoramento que não apresentem rápido esverdeamento dos tubérculos (Reeves, 1988). Porém, para selecionar adequadamente esses genótipos, não basta que a característica seja herdável; é preciso também mensurá-la com eficiência. O esverdeamento dos tubérculos tem sido avaliado, na maioria das vezes, por meio de escalas visuais aleatórias (Akeley et al., 1962). Entretanto, a intensidade de verde, atribuída a cada ponto dessas escalas, é um valor subjetivo, e por isso, não apresenta a reprodutibilidade desejada. $\mathrm{O}$ uso corrente $\mathrm{e}$ prático é a comparação da reação ao esverdeamento dos tubérculos do clone a um padrão de reação conhecida como 'Kennebec', utilizada como padrão nos Estados Unidos (Reeves et al., 1985). No Brasil, porém, não encontramos uma cultivar padrão ou referência.

Neste trabalho visou-se testar a eficiência de um método de avaliação, simples e rápido, da resistência de genótipos de batata ao esverdeamento dos tubérculos, e, simultaneamente, aplicar o método a clones superiores selecionados na Embrapa-Centro Nacional de Pesquisa de Hortaliças para resistência à pinta-preta.

\section{Material e Métodos}

Tubérculos de batata de 28 clones-elite e das cultivares Achat e Bintje, utilizadas como testemunhas suscetível e resistente (Spoladore et al., 1983), respectivamente, foram colhidos em 22 de setembro de 1997. Vinte e quatro horas após a colheita, foram expostos a ambiente de luz natural (porém prevenindo-se a incidência de sol), suplementada por quatro lâmpadas fluorescentes de $40 \mathrm{~W}$ cada, colocadas cerca de $2 \mathrm{~m}$ acima dos tubérculos. O experimento foi instalado em delineamento inteiramente casualizado, com três repetições e cinco tubérculos por parcela, cada uma colocada sobre papel-toalha, de cor creme. A intensidade de luz durante o experimento foi medida diariamente com luxímetro em três horários, às $8 \mathrm{~h}, 13 \mathrm{~h}$ e $16 \mathrm{~h} 30$, em sete pontos: nos quatro cantos do laboratório onde foi montado o experimento, e em três pontos sobre a mesa onde foram colocadas as parcelas experimentais. A intensidade média de luz no laboratório, durante o período em que foi conduzido o experimento, foi de 250 lux.

As avaliações da intensidade de esverdeamento dos tubérculos foram realizadas após $5,10,15$ e 20 dias de exposição dos tubérculos à luz. A quantificação do esverdeamento foi feita atribuindo-se uma única nota à parcela de cinco tubérculos. O padrão de notas foi obtido em uma etapa anterior à avaliação do experimento, a partir da exposição à luz natural de tubérculos de batata da cultivar Achat por 0 (sem exposição), 5, 10, 15, 20 e 25 dias, gerando as notas 1 (ausência completa de esverdeamento), 3 (esverdeamento fraco), 5 (esverdeamento médio), 7 (esverdeamento forte) e 9 (esverdeamento muito forte), respectivamente

Os tubérculos dos genótipos em avaliação, das cultivares utilizadas como testemunha e da cultivar utilizada para geração da escala de notas foram lavados antes da exposição à luz, com a intenção de simular o que ocorre em supermercados e demais postos de comercialização a varejo. Os clones incluídos no presente experimento foram selecionados pela sua resistência à pinta-preta (Brune et al., 1990; Brune \& Reifschneider, 1992; Brune et al., 1994) e pelas boas características agronômicas dos tubérculos, tanto para comercialização in natura, quanto para industrialização

Foi feita análise de variância de cada data de leitura sobre os valores de notas transformados para raiz quadrada. A média de cada genótipo foi então utilizada para a análise de agrupamentos, utilizando distância Euclidiana 
simples para cálculo da matriz de coeficientes, e o método da média de grupo, para realização do agrupamento. Foi feito um agrupamento para cada data de avaliação. Realizou-se, ainda, uma análise por componentes principais, buscando identificar a variabilidade resumida no primeiro componente principal e determinar a variabilidade disponível em cada data de avaliação.

\section{Resultados e Discussão}

Observaram-se notáveis diferenças na resistência ao esverdeamento dos tubérculos entre os clones em avaliação. Essas diferenças foram significativas em todas as datas de avaliação. Foi possível encontrar os padrões de resistência e suscetibilidade, cultivares Bintje e Achat, respectivamente, em classes distintas, já na primeira avaliação, após cinco dias de exposição à luz (Tabela 1). A distinção entre as duas testemunhas foi completa, ao longo de todo o experimento, o que garante a eficiência da análise de agrupamentos na classificação dos demais genótipos.
O esverdeamento dos tubérculos expostos à luz começa, na verdade, bastante antes do quinto dia. Já no primeiro dia de exposição à luz, os amiloplastos presentes na película dos tubérculos iluminados começam a transformar-se em cloroplastos, e as primeiras indicações de atividade fotossintética já podem ser percebidas com aumento dos teores de clorofila e carotenóides nos tubérculos (Zhu et al., 1984; Muraja-Fras et al., 1994). Entretanto, até que a quantidade de clorofila acumulada seja suficiente para produzir as primeiras alterações visíveis de coloração na película do tubérculo, são necessários mais alguns dias. Kaaber (1993), trabalhando com as cultivares Saturna e Beate, não percebeu nas primeiras 27 horas após a colheita alterações na coloração de tubérculos deixados sob iluminação natural, no campo; e para diferenciar significativamente a cultivar Bintje, resistente ao esverdeamento, da cultivar Kerrs Pinkers, suscetível, foram necessários seis dias de iluminação contínua, com uma intensidade de luz de 8.000 lux. Para Maine et al. (1988), porém, 42 horas de

Tabela 1. Agrupamento dos clones de batata (Série CNPH) e das testemunhas, cultivares Achat e Bintje, em razão do esverdeamento dos tubérculos após 5, 10, 15 e 20 dias de exposição à luz. Números entre parênteses referem-se à intensidade de esverdeamento. Brasília, Embrapa-CNPH, 1999(1).

\begin{tabular}{|c|c|c|c|c|c|}
\hline Grupo & 5 dias & 10 dias & 15 dias & 20 dias & $\begin{array}{c}\text { Componente } \\
\text { principal }\end{array}$ \\
\hline I & $\begin{array}{l}\text { Bintje, 024, 036, } \\
065(1,00)\end{array}$ & $\begin{array}{l}\text { Bintje, 036, } 065 \\
(1,00-1,33)\end{array}$ & $\begin{array}{l}\text { Bintje, 009, 036, } 065 \\
(2,00-2,67)\end{array}$ & $036(2,00)$ & $\begin{array}{l}\text { Bintje, 036, } 065 \\
(2,42-2,65)\end{array}$ \\
\hline II & $\begin{array}{l}009,030,039 \\
063(1,67-2,00)\end{array}$ & $\begin{array}{l}009,019,024,063 \\
(2,00-2,33)\end{array}$ & $\begin{array}{l}004,019,024,030,039 \\
061,063(3,00-4,00)\end{array}$ & $\begin{array}{l}\text { Bintje, 039, 063, } \\
065(2,67-3,33)\end{array}$ & $\begin{array}{l}009,019,024,030 \\
039,063(3,11-3,51)\end{array}$ \\
\hline III & $\begin{array}{l}004,019,061 \\
(2,33)\end{array}$ & $\begin{array}{l}002,004,006,013,020, \\
030,038,039,050,061, \\
069,084(2,67-3,67)\end{array}$ & $\begin{array}{l}013,038,047,050,069 \\
084(4,33-5,00)\end{array}$ & $\begin{array}{l}004,009,013,019, \\
024,030,050,061, \\
069(3,67-4,67)\end{array}$ & $\begin{array}{l}004,013,050,061, \\
069(3,66-3,85)\end{array}$ \\
\hline IV & $\begin{array}{l}\text { Achat, 002, 003, } \\
006,013,016, \\
018,020,031,033, \\
038,043,047,050, \\
060,066,068,069, \\
084(2,67-4,00)\end{array}$ & $\begin{array}{l}\text { Achat, 003, 016, 018, } \\
031,047,060,066,068 \\
(4,33-5,00)\end{array}$ & $\begin{array}{l}\text { Achat, } 002,003,006,016 \text {, } \\
018,020,031,033,043 \text {, } \\
060,066,068 \\
(5,33-7,00)\end{array}$ & $\begin{array}{l}003,006,018,020, \\
033,038,043,047, \\
060,068,084 \\
(5,00-6,33)\end{array}$ & $\begin{array}{l}\text { Achat, 002, 003, 006, } \\
018,020,038,047, \\
060,068,084 \\
(4,02-4,51)\end{array}$ \\
\hline $\mathrm{V}$ & - & $033,043(5,67-6,00)$ & - & $\begin{array}{l}\text { Achat, 002, 016, } \\
031,066 \\
(6,67-7,33)\end{array}$ & $\begin{array}{l}016,031,033,043, \\
066 \\
(4,62-4,75)\end{array}$ \\
\hline
\end{tabular}

(1) Notas correspondentes à intensidade de esverdeamento dos tubérculos: 1: ausência completa de esverdeamento; 3: esverdeamento fraco; 5: esverdeamento médio; 7: esverdeamento forte; 9: esverdeamento muito forte. 
exposição contínua a uma intensidade de 9.600 lux foram suficientes para diferenciar as cultivares Maris Piper e Désirée de outras de esverdeamento mais rápido.

No presente trabalho, utilizou-se propositadamente uma intensidade de luz bastante inferior, 250 lux, e ainda assim houve diferenciação dos padrões de resistência e suscetibilidade já com cinco dias. O objetivo principal neste trabalho não foi induzir o rápido esverdeamento dos tubérculos, mas utilizar condições indutoras que fossem facilmente obtidas, e, por conseguinte, pudessem ser reproduzidas ao longo do programa de melhoramento e também por todos os interessados em avaliar a característica.

Além da cultivar Bintje, alguns clones foram também classificados como resistentes ao esverdeamento dos tubérculos já na primeira data de avaliação: CNPH-024, CNPH-036 e CNPH-065 (Tabela 1). Caso o experimento não tivesse progredido, poderse-ia dizer que cinco dias de exposição à luz foram suficientes para caracterizar os genótipos quanto a sua resistência ao esverdeamento dos tubérculos. Essa rapidez na avaliação, associada à facilidade da atribuição de notas às parcelas experimentais, torna este método bastante prático, e recomendável para situações em que haja um grande número de genótipos a serem avaliados, onde o objetivo principal seja identificar os genótipos mais suscetíveis para que sejam eliminados, ou onde for possível assegurar que, no advento da liberação de uma cultivar, os tubérculos serão não só comercializados, mas também consumidos em, no máximo, cinco dias após a sua lavação. Entretanto, para as condições brasileiras, embora a comercialização possa acontecer dentro deste prazo, especialmente quando a zona de pro- dução está próxima dos centros de consumo, deve sempre ser considerado um prazo médio maior (Spoladore et al., 1983).

Com o progredir do experimento além dos cinco dias iniciais, sempre utilizando a cultivar Bintje como referência, observou-se que, dos três genótipos agrupados na mesma classe de resistência ao esverdeamento dos tubérculos desta cultivar na primeira data de avaliação, apenas um, o clone CNPH-065, apresentou comportamento semelhante ao da cultivar ao longo de todo o experimento (Tabela 1). O clone CNPH-024, à medida que o tempo de avaliação avançou, apresentou um esverdeamento progressivo dos tubérculos, distanciando-se da reação de resistência típica da cultivar Bintje, embora tenha mostrado, em todas as datas de avaliação, uma reação bem superior à da cultivar Achat, utilizada como padrão de suscetibilidade (Tabela 2). Verificouse que, na identificação de genótipos com níveis extremamente altos de resistência ao esverdeamento dos tubérculos, caso do clone CNPH-036, o progredir da avaliação além dos cinco dias iniciais também foi necessário. Foi apenas na última avaliação, 20 dias após o início da exposição à luz, que este clone colocou-se em uma classe à parte dos demais, pois foi mais resistente ao esverdeamento dos tubérculos do que a cultivar Bintje e do que o clone $\mathrm{CNPH}-065$ (Tabela 2). O comportamento dos clones $\mathrm{CNPH}-024$ e CNPH-036 mostra que uma única avaliação do esverdeamento de tubérculos com cinco dias após o início da exposição à luz, embora possa separar genótipos suscetíveis de resistentes, é insuficiente para identificar fontes de resistência realmente úteis a trabalhos de melhoramento.

Tabela 2. Notas de esverdeamento e grupo dos tubérculos de batata após exposição à luz, dos clones identificados como resistentes e moderadamente resistentes, e das testemunhas, cultivares Bintje e Achat. Brasília, Embrapa-CNPH, $19999^{(1)}$.

\begin{tabular}{|c|c|c|c|c|c|c|c|c|}
\hline \multirow[t]{2}{*}{ Genótipo } & \multicolumn{2}{|c|}{5 dias } & \multicolumn{2}{|c|}{10 dias } & \multicolumn{2}{|c|}{15 dias } & \multicolumn{2}{|c|}{20 dias } \\
\hline & $\operatorname{Nota}^{(1)}$ & Grupo & $\operatorname{Nota}^{(1)}$ & Grupo & $\operatorname{Nota}^{(1)}$ & Grupo & $\operatorname{Nota}^{(1)}$ & Grupo \\
\hline CNPH-009 & 1,7 & II & 2,3 & II & 2,7 & I & 4,7 & III \\
\hline CNPH-019 & 2,0 & III & 2,0 & II & 3,7 & II & 3,7 & III \\
\hline CNPH-024 & 1,0 & I & 2,3 & II & 4,0 & II & 4,7 & III \\
\hline CNPH-036 & 1,0 & I & 1,0 & I & 2,0 & I & 2,0 & I \\
\hline CNPH-039 & 1,5 & II & 2,5 & III & 3,3 & II & 3,3 & II \\
\hline CNPH-063 & 1,7 & II & 2,3 & II & 3,0 & II & 3,0 & II \\
\hline CNPH-065 & 1,0 & I & 1,3 & I & 2,3 & I & 2,7 & II \\
\hline Bintje & 1,0 & I & 1,0 & I & 2,2 & I & 2,7 & II \\
\hline Achat & 3,0 & IV & 4,3 & IV & 6,7 & IV & 8,7 & V \\
\hline
\end{tabular}

(1) Notas correspondentes à intensidade de esverdeamento dos tubérculos: 1: ausência completa de esverdeamento; 3: esverdeamento fraco; 5: esverdeamento médio; 7: esverdeamento forte; 9: esverdeamento muito forte. 
São escassos, na literatura, os trabalhos que apresentam avaliação progressiva de genótipos e, entre esses, são raros os que ultrapassam dez ou quinze dias. Spoladore et al. (1983) avaliaram o esverdeamento de tubérculos de uma série importante de cultivares utilizadas no Brasil, entre elas Achat, Bintje e Baraka, mas em uma única data, 25 dias após a colheita. Assim, Kaaber (1993) avaliou as cultivares Bintje e Kerrs Pinkers com seis e doze dias de exposição à luz, e encontrou resultados semelhantes em ambas as datas. Maine et al. (1988) e Reeves (1988) avaliaram também diversas cultivares, mas somente em uma única data, assim como Parfitt \& Peloquin (1981), que não utilizaram cultivares, mas genótipos experimentais. Somente Akeley et al. (1962) avaliaram os genótipos por um período maior de tempo - 2, 20, 41 e 60 dias - e concluíram que a primeira data de avaliação era muito precoce para distinguir corretamente os genótipos, o que acontecia de forma satisfatória tanto após 20 , quanto após 41 dias de exposição à luz, e que não houve alterações no teor de clorofila dos tubérculos após esta data.

No presente trabalho, observou-se, ainda, que alguns genótipos, como, por exemplo, os clones CNPH-039 e CNPH-063, agrupados na classe imediatamente inferior à da cultivar Bintje, mostraram, ao longo do experimento, resistência moderada mas consistente ao esverdeamento de tubérculos (Tabela 2). Revees (1988), quando avaliou cultivares em dois anos distintos, também encontrou pouca variação entre cultivares, e menos variabilidade, ainda quando comparados os tubérculos de uma mesma cultivar, o que mostra que os fenótipos são relativamente consistentes, apesar da herança quantitativa da característica (Akeley et al., 1962). Genótipos com esse tipo de reação não devem ser desprezados, em especial quando houver poucos genótipos disponíveis para prosseguir o programa de melhoramento, ou, ainda, quando apresentarem alguma outra característica de valor. Dos genótipos remanescentes, cabe destacar ainda os clones CNPH-009 e CNPH-019 (Tabela 2), que apresentaram bom valor per se, mas que não devem ser utilizados para fins de melhoramento, devido ao comportamento instável observado ao longo das avaliações.

Pôde-se verificar, através da análise realizada com componentes principais, que todas as quatro avaliações contribuíram, de forma definitiva, para a composição do primeiro componente principal, que reuniu $87 \%$ da variabilidade apresentada pelos dados, e que, pela sua natureza, representou, basicamente, a curva de esverdeamento dos tubérculos ao longo do tempo. Esse resultado, embora favorável à primeira vista, já que permite a utilização dos resultados do primeiro componente principal para realizar a análise de agrupamentos e de lá retirar os genótipos desejados, não pode ser interpretado totalmente desta forma, especialmente porque a intensidade de esverdeamento dos tubérculos é mais importante do que a velocidade com que o esverdeamento acontece. Assim, caso os genótipos fossem selecionados com base exclusivamente nas classes resultantes do agrupamento realizado com os valores do primeiro componente principal (Tabela 1), apenas os clones $\mathrm{CNPH}-036$ e CNPH-065, agrupados na mesma classe da cultivar Bintje, seriam levados em consideração. Se, para aumentar o número de genótipos selecionados, também a classe imediatamente inferior à da cultivar Bintje fosse selecionada, estariam sendo incluídos alguns outros clones, entre eles o clone CNPH-024, que, como foi visto, não apresentou resistência estável ao longo do tempo (Tabelas 1 e 2), além dos clones $\mathrm{CNPH}-009$ e CNPH-019, que, conforme já considerado, apresentaram comportamento bastante instável (Tabelas 1 e 2). Esses clones, mesmo sendo genótipos de bom valor per se, não deveriam ser incluídos em programas de melhoramento.

Outro objetivo para a realização da análise de componentes principais foi verificar se uma das datas de avaliação responderia por uma quantidade significativamente maior da variabilidade total obtida nas quatro leituras, de modo que essa data de avaliação pudesse ser indicada, em experimentos futuros, como uma única avaliação, tornando o método ainda mais prático. Porém, observou-se que as datas de avaliação proporcionaram quantidades bastante semelhantes de variabilidade, todas em torno de $25 \%$ da variabilidade total observada. Dessa forma, recomendase que o número de avaliações e a duração de futuros experimentos seja determinada levando-se em consideração seus objetivos e o tempo médio gasto entre a colheita e o consumo dos tubérculos.

\section{Conclusões}

1. O método utilizado é eficiente para separar genótipos resistentes dos suscetíveis, com cinco dias de exposição dos tubérculos à luz.

2. Para identificação adequada de fontes de resistência, é necessário prosseguir com a avaliação até 20 dias de exposição dos tubérculos à luz. 
3. A utilização do primeiro componente principal, que representa a curva de esverdeamento dos tubérculos, não é adequada para selecionar genótipos resistentes, melhor representados pela análise da intensidade de esverdeamento.

4. As diferentes épocas de avaliação da intensidade de esverdeamento dos tubérculos apresentam a mesma importância relativa na formação do primeiro componente principal.

\section{Referências}

AKELEY, R. V.; HOUGHLAND, G. V. L.; SCHARK,A. E Genetic differences in potato tuber greening. American Potato Journal, Orono, v. 39, p. 409-417, 1962.

BROWN, E.; RILEY,W. Greening of potato tubers: varietal response to controlled exposure to light. National Institute of Agricultural Botany Journal, Cambridge, Grã-Bretanha, v. 14, p. 70-76, 1976.

BRUNE, S.; MELO, P. E. de; LIMA, M. F. Resistência aAlternaria solani: características agronômicas e qualidade de fritura em clones de batata imunes a PVY ePVX. Horticultura Brasileira, Brasília, v. 12, n. 2, p. 125-130, 1994.

BRUNE, S.; REIFSCHNEIDER, F. J. B. Identificação de fontes de resistência à pinta-preta em batata. Horticultura Brasileira, Brasília, v. 10, n. 2, p. 100-102, 1992.

BRUNE, S.; REIFSCHNEIDER, F. J. B.; BUSO, J. A Resistência de genótipos de batata (Solanum tuberosum) à pinta-preta (Alternaria solani). Fitopatologia Brasileira, Brasília, v. 15, n. 4, p. 297-299, 1990.

CONOVER, J. C.; PRYKE, J. A. Plastid and nuclear DNA in potato tuber tissue during greening. Journal of Experimental Botany, Oxford, v. 38, n. 192, p. 1219-1227, 1987.

DALE, M. F. B.; MACKAY, G. R.; BRADSHAW, J. E. Inheritance of table and processing quality. In: MacKAY, G. R. (Ed.). Potato genetics. Wallingford : CAB International, 1994. p. 285-315.

DAO, L.; FRIEDMAN, M. Chlorophyll, chlorogenic acid glycoalkaloid, and protease inhibitor content of fresh and green potatoes. Journal of Agricultural and Food Chemistry, Washington, v. 42, n. 3, p. 633-639, 1994.

GRIFFITHS, D. W.; DALE, M. F. B.; BAIN, H. The effect of cultivar, maturity and storage on photo-induced changes in the total glycoalkaloid and chlorophyll contents of potatoes (Solanum tuberosum). Plant Science, Limerick, v. 98, n. 1, p. 103-109, 1994.
GUARDA, G. Obiettivi e primi risultati del miglioramento genetico della patata per gli ambienti del nord Italia. Informatore Agrario, Verona, v. 42, p. 55-57, 1986.

KAABER, L. Glycoalkaloids, green discoloration, and taste development during storage of some potato varieties (Solanum tuberosum L.). Norwegian Journal of Agricultural Sciences, Aas, v. 7, n. 2, p. 221-229, 1993.

MAINE, M. J. de; BAIN, H.; JOYCE, J. A. L. Changes in the total tuber glycoalkaloid content of potato cultivars when exposed to light. Journal of Agricultural Science, Cambridge, Grã-Bretanha, v. 111, n. 1, p. 57-58, 1988.

MURAJA-FRAS, J.; KRSNIK-RASOL, M.; WRISCHER, M. Plastid transformation in greening potato tuber tissue. Journal of Plant Physiology, Jena, v. 144, n. 1, p. $58-63,1994$

PARFITT, D. E.; PELOQUIN, S. J. The genetic basis for tuber greening in 24-chromosome potatoes. American Potato Journal, Orono, v. 58, n. 6, p. 299-304,1981.

REEVES,A. F. Varietal differences in potato tuber greening. American Potato Journal, Orono, v. 65, p. 651-658, 1988.

REEVES, A. F.; CUNNINGHAM, C. E.; NICKSON, R. L.;AKELEY, R. V.; MURPHY, H. J.; MANZER, F. E.; TRUE, R. H. Campbell 14: a Verticillium resistant round white potato variety. American Potato Journal, Orono, v. 62, n. 5 , p. $215-220,1985$.

SPOLADORE, D. S.; TEIXEIRA, J. P. F.; ZULLO, M. A. T.; TEIXEIRA, P. R. M.; MIRANDA FILHO, H. S. Ocorrência de glicoalcalóides e esverdeamento em tubérculos de batata recém-colhidos e armazenados. Bragantia, Campinas, v. 42, p. 221-231, 1983.

TAN, S. C.; HAYNES, Y. S. Reduction of greening in Atlantic and Cadima potatoes. In: AUSTRALASIAN POSTHARVEST HORTICULTURE CONFERENCE FOR SCIENCE AND TECHNOLOGY FOR THE FRESH FOOD REVOLUTION, 1995, Melbourne. Proceedings... Melbourne : Institute for Horticultural Development, 1996. p. 295-301

ZAN, F. del; BARUZZINI, L. Sintomatologia, cause e controllo delle principali alterazioni fisiologiche del tubero di patata. Informatore Agrario, Verona, v. 47, p. 65-72, 1991.

ZHU, Y. S.; MERKLE-LEHMAN, D. L.; KUNG, S. D. Light-induced transformation of amyloplast into chloroplasts in potato tubers. Plant Physiology, Rockville, v. 75 , n. 1 , p. $142-145,1984$. 